\title{
LOS MEDIOS Y LAS REDES EN MÉXICO DURANTE LA GESTACIÓN DE Cien años de soledad (1961-1967), DE GARCía MÁrQuEZ*
}

\author{
Mexican Media and Editorial \\ Networks in the Gestation of García \\ MÁrquez's ONE HundREd YEARS OF SOLITUdE \\ (I96I-I967)
}

* Cómo citar este artículo: Pineda Buitrago, S. (2021). Los medios y las redes en México durante la gestación de Cien años de soledad (1961-1967), de García Márquez. Estudios de Literatura Colombiana 49, pp. 71-86. DOI: $\underline{\text { https://doi.org/10.17533/udea.elc.n49a04 }}$

1 https://orcid.org/0000-0002-0701-5892 sebasconection@gmail.com Universidad Iberoamericana Puebla, México.

Editores: Andrés Vergara Aguirre, Christian Benavides Martínez

Recibido: 15.08 .2020

Aprobado: 28.10.2020

Publicado: 18.12 .2020

Copyright: (02021 Estudios de Literatura Colombiana. Este es un artículo de acceso abierto distribuido bajo los términos de la Licencia Creative Commons AtribuciónNo comercial - Compartir igual 4.0 Internacional

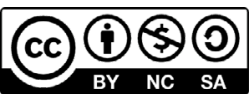

Resumen: El propósito de este artículo es pensar la gestación de Cien años de soledad (1965-1967) como un desafío de la "ciudad letrada" a la "ciudad audiovisual". Tal novela fue escrita bajo las condiciones materiales de la Guerra Fría en el contexto sociopolítico de México. Coincide con la emergencia de la televisión, pero también con el fin de la época dorada del cine mexicano. Si "los medios determinan nuestra situación" (Kittler, 1999, p. xxxix), este artículo se pregunta si el impacto de la tecnología audiovisual tuvo como respuesta los manuscritos de Melquíades: la milenaria hegemonía textual de la "memoria histórica".

Palabras claves: redes intelectuales; arqueología de los medios; Cien años de soledad; cine; televisión.

Abstract: The purpose of this article is to consider the gestation period of One Hundred Years of Solitude (1965-1967) as a challenge of the "lettered city" to the "audiovisual city". This novel was written under the material conditions of the Cold War in the sociopolitical context of Mexico. It coincides with the emergence of television, but also with the end of the Golden Age of Mexican cinema. If "media determines our situation" (Kittler, 1999, p. xxxix), this article questions whether the impact of audiovisual technology resulted in the Melquíades' manuscripts: the millennial textual hegemony of "historical memory".

Keywords: intellectual networks; media archeology; One Hundred Years of Solitude; cinema; television. 


\section{Presentación}

La principal pregunta de investigación que intentaremos contestarnos es si Cien años de soledad constituye un desafío de la "ciudad letrada" a la "ciudad audiovisual", es decir, un éxito tanto literario como comercial para contrarrestar el impacto tecnológico de los medios de entretenimiento audiovisual. Pues, aunque García Márquez nunca abandonó la escritura de guiones ni la pasión por la imagen cinematográfica, en una entrevista concedida en 1972 afirmó que empezó a escribir Cien años de soledad "contra el cine, en el sentido de demostrar que la literatura tiene mucho más alcance, mayores posibilidades de llegar a todo el mundo" (citado por Rocco, 2014, p. 16). No es la "cultura letrada", sino la audiovisual la que inicialmente formó a García Márquez, "a member of the first generation in history for whom the cinema, including talking films, was an experience prior to written literature" (Martin, 2009, p. 54). Esta previa cultura audiovisual de la generación de García Márquez, que implicó la incorporación de los recursos del lenguaje cinematográfico a la prosa narrativa, fue juzgada de manera negativa por Ángel Rama en el ensayo "La tecnificación narrativa" (1981). En él, observó que los narradores del boom habían extrapolado técnicas y sistemas de obras europeas o angloamericanas, pero sin el contexto filosófico que las había hecho posibles, es decir, "lejos del significado etimológico que para los griegos hacía de una 'tecné' una epistemología” (Rama, 1981, p. 32). Para el autor de La ciudad letrada, Cien años de soledad constituía una "nivelación rigurosa y equivalente de los datos realistas y fantásticos dentro de una fluencia coloquial, de tal modo que la historia deviene un discurso, atribuible al narrador o al texto críptico de Melquíades” (p. 80). En la crítica de Rama, por desdicha, la preocupación por el cine y la imagen es marginal. Acaso Rama fue víctima de lo que Martin Jay (2007) observó en gran parte del pensamiento francés del siglo xx, esto es, un intento sistematizado por reducir la imagen a signos semióticos; más aún, una "desnarrativización de lo ocular", cuyo punto culminante es la aparición del arte abstracto (p. 46). En cualquier caso, la idea de una "tecnificación narrativa" revela en Rama una preocupación por los medios: una cercanía al estructuralismo más que al existencialismo. El uruguayo ya no hablaba tanto de "conciencia" o "sujeto", sino de "reglas", "códigos", "sistemas" para entender la crisis del escritor y del intelectual dentro del campo literario de los años sesenta (Gilman, 2003, p. 19). Si se supone que el sujeto no construye el sentido, sino que este es anterior a aquel, conviene apoyarse en una teoría posestructuralista mucho más preocupada por la objetividad 
o materialidad de los medios. Acaso así se pueda entender la compleja relación de García Márquez con la cultura audiovisual y las redes editoriales o la "ciudad letrada".

\section{Amigo-enemigo: cine y televisión versus "alta literatura"}

Los puntos culminantes de la gran literatura del siglo $\mathrm{xx}$ se encuentran relacionados con los momentos en los cuales el cine y la televisión se asumieron con suma claridad como enemigos (Kittler, 2010, p. 36). La dialéctica del amigo-enemigo indica que este último es la encarnación de nuestra propia pregunta: "Der Feind ist unsere eigene Frage als Gestalt" (p. 36). No se trata, al pensar el cine y la televisión como enemigos, de despreciarlos en nombre de la "alta cultura" encarnada en la lectura literaria o filosófica, tal cual podría pensarse por el famoso capítulo de Adorno y Horkheimer en Dialéctica de la Ilustración, "El cine: Ilustración para masas", sino de situarse en su propio nivel. Para Kittler (2010), desde una posición post-hermenéutica, nuestros órganos de los sentidos son procesadores de señales relativamente débiles, y nada sabemos de ellos si los medios técnicos no nos proporcionan modelos y metáforas (p. 34). Si la facilidad de la escritura vocálica o alfabética para reproducir el habla humana en signos gráficos fue entre los griegos el sustrato material del alma (del estudio del ser), el medio para popularizar la Ilíada y la Odisea y estandarizar la democracia ateniense, a partir de 1900 semejante predominio de la escritura se vio desafiado. El cine estandarizó las imágenes en movimiento (fotos y pinturas) en tanto el principal medio para almacenar, procesar y difundir la realidad y la fantasía (lo que los antiguos griegos llamaban el "alma”), amenazando o dejando en entredicho el pasado, la "memoria histórica”.

A condición de ser una hipótesis susceptible de discusión, Cien años de soledad es la respuesta heurística al impacto tecnológico de los medios de entretenimiento audiovisual. Sentado en un cuartito oculto de la casa de los Buendía, Melquíades redacta en sánscrito el comienzo, auge y decadencia de Macondo, cuya desaparición coincide con la emergencia del tren, el avión y los medios de entretenimiento audiovisual. En las primeras páginas de la novela aparecen los gitanos pregonando por Macondo un catalejo y una lupa del tamaño de un tambor, que exhiben como el último descubrimiento de los judíos de Ámsterdam, y que Melquíades se atreve a describir como un antecedente de la televisión avant la lettre: "Dentro de poco, el hombre podrá ver lo que ocurre en cualquier lugar de la tierra, sin moverse de su casa" (García Márquez, 2007, p. 11). ¿No alude, en efecto, a la televisión? 
Para 1961, cuando Gabriel García Márquez arribó a la Ciudad de México, el aparato televisivo comenzaba a penetrar en el hogar de cada familia mexicana (Sánchez Ruiz, 1991, p. 238). En unión con una serie de capitales privados, el Estado mexicano monopolizó la concesión de la televisión comercial a condición de la importación en masa de tales aparatos electrónicos. Además de los instalados en los hogares, los ávidos empresarios pidieron que se ubicaran televisores en restaurantes, bares, vestíbulos de teatros y hasta de cine, con tal de asegurarse cuñas publicitarias (Hernández Lomelí, 2002, p. 335). El empresario automotriz Rómulo O’Farril Silva compró varios kinetoscopios (cámaras de cine acopladas al monitor de la televisión) y obtuvo el permiso para fundar Televisión de México S. A. en asociación con el presidente Miguel Alemán.

Las teorías sociológicas sobre la televisión en tanto mass media se estrellan contra una pared y quedan en un callejón sin salida si ignoran que el contenido audiovisual depende de una tecnología óptica que, mediante las condiciones fisiológicas y psicológicas del ojo humano, adapta a la pantalla un pequeño matiz del enorme espectro electromagnético. Tal tecnología óptica la describió el ingeniero angloamericano del laboratorio de investigación de AT\&T, Claude Edwood Shanon, en The Mathematical Theory of Communication, a partir de los dispositivos militares como el radar y las tecnologías de la radio que hicieron posible la transmisión de imágenes por cable (Kittler, 2010, p. 43). Incluso mucho antes, a partir de la invención de la metralleta, patentada por el angloamericano Richard Jordan Gatling el 9 de mayo de 1862, el francés Étienne Jules Marey se inspiró para inventar en 1882 el fusil fotográfico o cronofotógrafo, capaz de disparar 12 imágenes por segundo (Virilio, 1991, p. 8). En adelante, las técnicas aeronáuticas y cinematográficas siempre han mantenido extrañas correspondencias que raramente han sido analizadas.

Mientras del nazismo alemán brotó un "culto a la tierra" y una geopolítica del Lebensraum (espacio vital), del fascismo italiano más bien surgió un "odio a la tierra inmunda” que ya está presente en 1909 en la obra Mafarka el futurista, de Filippo Tommaso di Marinetti (Virilio, 1986, p. 4). Pues en el cine neorrealista italiano aún persiste un culto a la ingravidez aeronáutica como correlato de la proyección filmica, es decir, las secuencias del fotograma cinematográfico se corresponden con la miniaturización analógica del punto de vista que se obtiene desde diez mil pies de altura. Si en Cien años de soledad el angloamericano Mr. Herbert construyó el ferrocarril de Macondo para esta- 
blecer las bananeras bajo una geopolítica expansionista (la de la United Fruit Company) fundada en la extracción de recursos naturales, Gastón, el aviador belga, quiso establecer el primer aeropuerto de Macondo. Gastón se había casado con Amaranta Úrsula en Bélgica, donde volaban juntos en un biplano deportivo, "compenetrados cuanto más minúsculos iban haciéndose los seres de la tierra” (García Márquez, 2007, p. 431). El fracaso de Gastón para construir el aeropuerto de Macondo, al advertir que sus socios habían enviado un avión al Congo belga confundidos por la comunidad de los makondos, anuncia el fin del pueblo y de la estirpe de los Buendía.

Las técnicas de lenguaje cinematográfico no son, en García Márquez, necesariamente apologéticas. En el episodio de la masacre de las bananeras, el narrador deja entrever que José Arcadio Segundo padeció el terrorismo de aquella matanza histórica ocurrida en 1928 no como una realidad comprobable, sino una ilusión cinematográfica:

Tratando de fugarse de la pesadilla, José Arcadio Segundo se arrastró de un vagón al otro, en la dirección en la que avanzaba el tren, y entre los relámpagos que estallaban por entre los listones de madera al pasar por los pueblos dormidos veía los muertos hombres, los muertos mujeres, los muertos niños que iban a ser arrojados como banano de rechazo (García Márquez, 2007, p. 348).

Esta percepción del movimiento del tren, que intenta alejarse de una tierra empobreci$\mathrm{da}$, gastada, y en la que el litoral constituye una salida, anuncia el abandono y la desaparición física de Macondo en virtud de los medios de transporte y comunicación. ¿Quién desea vivir allí si ya pasa el tren? "Aquí no ha habido muertos”(p. 350), le dice una mujer con la que se encuentra José Arcadio Segundo al llegar a Macondo después de la masacre de las bananeras. ¿Es posible que José Arcadio Segundo haya creído ver una ilusión cinematográfica, de noche, causada por el movimiento del ferrocarril? Pero incluso tratándose de una ilusión cinematográfica genera en el personaje y en el lector la sensación de un terrorismo si se quiere inmaterial, el control de los campos de percepción.

Las relaciones entre ferrocarril y cine se remontan a la primera película del cineasta francés Louis Lumière, L'Arrivée d'un train en gare de La Ciotat (1895-1896). Esta película fundacional dio inicio al giro perceptivo, esto es, a la posibilidad contar con la ilusión óptica como parte de lo cultural y con la capacidad de modificar el ethos particular de un lugar (Ligensa, 2015, p. 2). Pues el cine es una tecnología bélica, de guerra, cuyo manejo permite el control de la percepción (Virilio, 1991, p. 10). El cine en cuanto técnica de guerra no está interesado en reportar victorias "materiales", sino en apropiarse de la "inmaterialidad" de los campos de percepción. 
Si el escritor de mediados del siglo xx quería competir con la velocidad de transmisión y la capacidad de seducción del cinematógrafo, no solo necesitaba ponerse al servicio del Estado total, de la ideología y del sentimentalismo, sino obligarse a practicar una "high literature" (Kittler, 1990, p. 267). Esta "alta literatura" como sinónimo de "alta cultura" tenía que ver menos con la erudición en sí que con la habilidad para narrar, para la invención y visualización de otras realidades mentales a las que no podía llegar el haz de luces de una pantalla televisiva o cinematográfica.

No en vano, desde sus primeros cuentos publicados en El Espectador en 1947, García Márquez confesó que un libro fundamental en su formación había sido La experiencia literaria [1941], de Alfonso Reyes (Cobo Borda, 2006, p. 160). Allí Reyes insiste en que el escritor no debe confiarse demasiado en la literatura cual si se tratara de un estado de alma y, en cambio, debe persistir mucho en la literatura como efecto de palabras para triunfar sobre el caos de las realidades exteriores (Reyes, 2004, p. 91). No hay que olvidar que Reyes fue uno de los primeros críticos cinematográficos en lengua española y que sus reseñas, publicadas entre 1915 y 1917 en el semanario España y en el diario El Imparcial, de Madrid, coinciden con la propaganda bélica de la Primera Guerra Mundial. En otras palabras, para legitimar la singularidad de un lenguaje personal, literario, distinto del filosófico, historiográfico, pedagógico o político, Reyes y García Márquez se presentan como epígonos de la profesión de escritor y de la autonomía de la literatura, sí, pero con unos límites porosos que no invitan sino a la transgresión. Es decir: la capacidad transgresora de la literatura supone un agotamiento de su propia especificidad, esto es, de su sentido. Pues la escritura no constituye un saber en sí mismo. No es una teoría sino una práctica, un método para acceder al conocimiento de cualquier género de realidad, incluida la cinematográfica.

La "oralidad secundaria" de los medios audiovisuales (radio, cine y televisión) depende de la programación de guiones y de instrucciones (Ong, 2006, p. 37). No hay modo de obviar dos milenios de hegemonía textual. Por consejo de Carlos Fuentes, según declaraciones de García Márquez recogidas por Germán Espinosa (2004), la exactitud verbal de los diálogos entre los personajes de Cien años de soledad proviene de una relectura del Refranero español (p. 158). Con lo cual, si el enemigo de la literatura es el mass media cinematográfico y televisivo, insistamos, es también el garante de la seriedad de la misma literatura. 


\section{Las redes audiovisuales versus las redes editoriales}

Desde el 14 de agosto de 1941 el ingeniero mexicano Guillermo González Camarena obtuvo en Estados Unidos la patente 2296019 por inventar un adaptador cromoscópico simplificado para la televisión (Corona Berkin, 1992, p. 201). Los empresarios mexicanos Rómulo O’Farril Silva y Emilio Azcárraga Vidaurreta (el posterior fundador de Televisa) rápidamente invirtieron en redes y antenas televisivas para monopolizar semejante medio (Hernández Lomelí, 2002, p. 333). ¿Supuso la televisión un desmedro de la "ciudad letrada"? La respuesta es más que obvia.

En 1948 el Instituto Nacional de Bellas Artes, INBA, nombró una comisión para redactar un informe sobre la introducción de la televisión en México. El ingeniero González Camarena formó parte de ella junto con el escritor Salvador Novo. Este último, en representación de la "cultura letrada”, se mostró muy escéptico del beneficio civil que pudiera traer semejante tecnología militar, y aún en un ensayo de 1967, La vida en México en el periodo presidencial de Miguel Alemán, afirmó que la televisión era "como una hija monstruosa del oculto coito entre la radio y el cine" (citado por Corona Berkin, 1992, p. 201). Esto quiere decir que para 1967 ya había entre cierta intelectualidad mexicana una enemistad declarada contra los medios audiovisuales, sin que necesariamente significara un rompimiento de relaciones entre escritores o artistas con cineastas y empresarios mediáticos. En la dialéctica amigo-enemigo, los escritores mexicanos más consagrados de la segunda mitad del siglo xx, desde Juan Rulfo pasando por Fuentes hasta José Emilio Pacheco, coquetearon con la industria cinematográfica.

Dado que los medios audiovisuales no se bastan a sí mismos si no se controlan también los medios impresos, O'Farril se adueñó también del diario Novedades, en cuyas páginas salió entre 1949 y 1961 el principal suplemento literario mexicano, México en la Cultura. En él, el domingo 9 de julio de 1961, García Márquez publicó su primer artículo en México a propósito del suicidio de Hemingway, "Un hombre ha muerto de muerte natural”. Pero no llegó García Márquez a trabajar con los O’Farril, puesto que el suplemento México en la Cultura fue cerrado en 1962 por el reportaje que publicaron Fernando Benítez y Carlos Fuentes acerca del asesinato del dirigente campesino Rubén Jaramillo (Cabrera López, 2013, p. 49). García Márquez comenzó a trabajar con otro empresario mexicano de los medios, Gustavo Alatriste, el productor de dos películas de Buñuel, Viridiana y El ángel exterminador, ambas ganadoras 
de Cannes en 1961 y 1962. Alatriste le abrió las puertas del cine mexicano a García Márquez con la condición de que nutriera de artículos el semanario Sucesos para todos (Rocco, 2014, p. 13). El que García Márquez no firmara ningún artículo en el semanario Sucesos para todos, si bien impide endilgarle la autoría de alguno, no imposibilita revisar el contenido y la edición de esta publicación que funcionaba a la manera de una "televisión textual", si cabe el término. Es decir: era un semanario con textos fáciles de leer y adecuados a las ilustraciones sobre el "suceder" nacional e internacional, del artístico y el científico, y hasta de lo paranormal, al grado de, parafraseando a Benjamin (2003, p. 40), sincronizar la sucesión de imágenes con la velocidad de la vida cotidiana. En cada número, por lo demás, se incluía la programación televisiva de los cinco canales que para entonces funcionaban en Ciudad de México.

Tras su paso por las revistas populares de Alatriste, García Márquez comenzó a trabajar a partir de 1963 en la agencia de publicidad Walter Thompson, una de las más antiguas y prestigiosas firmas angloamericanas radicadas en México. Allí se familiarizó con las técnicas de marketing utilizadas para atraer la atención de una clase media mexicana en rápida expansión, y aprendió a diseñar lemas, eslóganes de gran impacto psicológico que más tarde aplicó para promocionar su obra, tales como el de “mi esposa escribe mis novelas", que llegó a ser titular de varios periódicos en agosto y septiembre de 1967, es decir, una vez advertido el éxito de Cien años de soledad (Santana Acuña, 2020, pp. 222-224). Pero esto no significa ni confirma el término peyorativo de garciamarqueting que le endilgaron colegas celosos. No. Solo ratifica que García Márquez advirtió que, desde principios de siglo xx, nos encontramos en un imperio de estándares, en una convergencia entre cine y vida, entre medialidad y realidad, en una simulación de la que solo una aguda lecto-escritura (la revelación de los manuscritos de Melquíades) podría develarnos el sentido de la Historia, esto es, de un tiempo que genera significado: memoria histórica.

Si Cien años de soledad fue escrita contra el cine, ello explicaría el desafío - y la inutilidad - para adaptarla a la pantalla cinematográfica. Aunque también fueron guionistas a su manera, algo similar se puede decir de Carlos Fuentes, Mario Vargas Llosa, Guillermo Cabrera Infante y José Emilio Pacheco, cuyas novelas escasamente han logrado adaptarse a la pantalla cinematográfica. Pacheco, por ejemplo, escribió los guiones para cuatro películas de Arturo Ripstein, El castillo de la pureza (1972), Fox trot (1976), El santo oficio (1973) y El lugar sin limites (1977), guiones de películas 
que muy pocos recuerdan y que en modo alguno opacan sus poemarios, libros de cuentos y novelas. Ya en su primera novela, Morirás lejos (1967), Pacheco inventó un dramaturgo frustrado por no saber cómo representar plástica o cinematográficamente la psicopatología de un nazi (Salmerón Tellechea, 2011, p. 71; Rocco, 2016, p. 25).

El guion del cortometraje La langosta azul, en el cual participó en 1954, es anterior a la publicación en 1955 de La hojarasca, su primera novela. En julio de 1955, cuando fue enviado a Génova como corresponsal de El Espectador, García Márquez pasó por Roma para tratar de matricularse en la Scoula Sperimentale di Cinematográfica, dirigida por Luigni Chiarini (Rocco, 2014, p. 11). Las técnicas neorrealistas se advierten en El coronel no tiene quien le escriba (1958), especialmente en el narrador omnisciente capaz de no perder de vista al protagonista y de sincronizar acciones concretas con diálogos lacónicos. Atraído por los Estudios Churubusco y por el capital estatal inyectado al cine mexicano, García Márquez se radicó en Ciudad de México a mediados de 1961. Para 1966 ya había escrito el guion de cinco películas: 1) El gallo de oro (1964), dirigida por Roberto Gavaldón y con fotografía de Gabriel Figueroa; 2) En este pueblo no hay ladrones (1964), dirigido por Alberto Isaacs; 3) Tiempo de morir (1965), dirigida por Arturo Ripstein; 4) Lola de mi vida (1966), dirigida por Miguel Barbachano Ponce, y 5) Juego peligroso (1966), dirigida por Luis Alcoriza. Aun cuando la época dorada del cine mexicano había pasado de moda ("El Indio" Fernández, María Félix), los directores y productores mexicanos no podían despojarse tan fácilmente de los estereotipos del nacionalismo revolucionario, en parte por la financiación estatal del priismo autoritario.

En cambio, luego de superar el aislamiento internacional y sin que aún cayera la dictadura franquista, las editoriales españolas comenzaron a extenderse por Hispanoamérica. Promovieron precisamente una narrativa más cosmopolita. En el cuarto capítulo de su libro Ascent to Glory. How One Hundred Years of Solitude Was Written and Became a Global Classic (2020), Álvaro Santana Acuña habla de una "creatividad en red" (networked creativity), esto es, de una red de agentes, editores, publicistas, corresponsales y revistas que animaron la famosa novela del colombiano escrita en Ciudad de México entre 1965 y 1966, posteriormente negociada con agentes españoles y publicada en la editorial Sudamericana de Buenos Aires en 1967. Pues, como comprueba Santana Acuña (2002, p. 108), la escritura de Cien años de soledad coincide con un boom comercial de editoriales españolas que se fundaron entre 1955 y 1969 : 
la colección Biblioteca Breve de Seix Barral en 1955; las editoriales Plaza y Janés y Anaya en 1959; Círculo de Lectores en 1962; Alfaguara en 1964; Alianza en 1966; Anagrama y Tusquets en 1969. A estas editoriales peninsulares habría que agregar las mexicanas Era, fundada en 1960, y Joaquín Mortiz, fundada en 1962, sin olvidar la argentina Sudamericana fundada en 1939 por españoles republicanos exiliados. De modo que conviene seguir indagando si lo que verdaderamente coincide con este esplendor editorial en general y de Cien años de soledad en particular es, en realidad, una competencia contra los medios audiovisuales, un desafío de la "ciudad letrada" para contrarrestar la masificación del cine y la televisión.

\section{La memoria audiovisual versus la memoria textual-histórica}

En una entrevista que sostuvo en 1973 con Elena Poniatowska (2017), García Márquez afirmó que la escritura y documentación de su famosa novela fue posible en virtud de una red de colegas y amigos que convivían con él en la capital mexicana, especificando que él "le hablaba [1lamaba] a José Emilio Pacheco: 'Mira, hazme el favor de estudiarme exactamente cómo era la cosa de la piedra filosofal”' (p. 70). La piedra filosofal, en efecto, aparece en el primer capítulo de Cien años de soledad. Melquíades, en su tercera visita a Macondo, le regala a José Arcadio Buendía un laboratorio de alquimia en prueba de la inteligencia de aquel por haber descubierto por sí mismo que la Tierra era redonda. Melquíades nutre el laboratorio del primer patriarca de los Buendía

[...] con muestras de los siete metales correspondientes a los siete planetas, las fórmulas de Moisés y Zósimo para el doblado del oro, y una serie de apuntes y dibujos sobre los procesos del Gran Magisterio, que permitían a quien supiera interpretarlos intentar la fabricación de la piedra filosofal (García Márquez, 2007 , p. I5).

Por esta pequeña mención de la piedra filosofal, el poco recordado crítico colombiano Luis Cova García, el 11 de mayo de 1969 en un artículo titulado “¿Coincidencia o plagio?”, publicado en El Espectador, acusó a García Márquez de plagiar La búsqueda de lo absoluto de Balzac, una novela filosófica de 1834; supuesto de plagio del que se valió Miguel Ángel Asturias para lo mismo (Bajarlía, 2012, p. 121). Pero el propio Pacheco (2014), en el artículo "Asturias y Gabriel García Márquez: Epílogo de una tragicomedia”, publicado en Excélsior el 16 de junio de 1971, aclaró que la única semejanza entre Balzac y García Márquez, tan remota que cancela hasta la simple sospecha de 
plagio, se limitaba al episodio del taller de alquimia y a la posibilidad de transformar el plomo en oro. Pacheco agregaba que la búsqueda alquímica que permitiría a los seres humanos igualar a los dioses, más que en el ilusorio daguerrotipo de Dios perseguido por José Arcadio Buendía, "concluyó fáusticamente en los infiernos de Hiroshima y Nagasaki" (párr. 9). Como veremos, Pacheco señalaba otra clave de interpretación.

Al tiempo que ayudaba a García Márquez en la documentación de Cien años de soledad, Pacheco se documentaba para su primera novela, Morirás lejos, publicada igualmente en 1967 en la editorial mexicana Joaquín Mortiz. La novela de Pacheco es una suerte de collage: las guerras judías con el Imperio romano (68-70, 132-135 d. C.), narradas por Flavio Josefo, conviven con memoria del holocausto nazi, narrado por un discreto dramaturgo de Ciudad de México llamado simplemente m. Morirás lejos también está sembrada de microrrelatos, cuya división entre uno y otro se indica mediante un ideograma y subtítulos alusivos a la Torá y al nazismo: "Salónica”, "Diáspora”, "Grossaktion”, “Totenbuch”, “Götterdämmerung”. Más allá de la coincidencia temporal de su publicación, en ambas novelas existe una preocupación común por la memoria histórica en desafío contra la inmediatez de los medios audiovisuales, especialmente de la industria cinematográfica y televisiva, cuya emergencia precisamente crecía a escalas industriales en la década de 1960.

Ahora bien, ¿de dónde surge el interés por la memoria histórica y especialmente por el Holocausto (la Shóa) en la época de la posguerra? El liberalismo, en el marco de la Guerra Fría, recibió la orden de enterrar el pasado nazi (Caspistegui, 2009, p. 54). El origen del concepto de memoria histórica aparece, en parte, para contrarrestar una idea de historia universal burguesa. Aparece en la tesis 17 de las 19 que Walter Benjamin dejó inéditas en Sobre el concepto de historia, un libro inacabado y que Pierre Missac, póstumamente, tradujo al francés y publicó en gran parte en la revista Temps Modernes en 1947. En la tesis 9 aparece el Angelus novus, el cuadro de Paul Klee cuya representación Benjamin extiende a una visión pesimista de la historia universal. Tal ángel tiene los ojos desorbitados, la boca abierta y las alas tendidas por un huracán que sopla desde el paraíso. "Este huracán es lo que nosotros llamamos progreso" (Benjamin, 2008, p. 45). ¿No parece un huracán la escena final de Cien años de soledad? Para Sultana Wahnón (1995), la historia de la familia revelada por Aureliano Babilonia en los manuscritos de Melquíades, es idéntica a la imagen del ángel de la historia que imaginó Benjamin basándose en el mencionado cuadro de Klee: 
De pie y con la mirada clavada en los manuscritos, es fácil atribuir al estupefacto Aureliano los mismos ojos desencajados y la misma boca abierta del ángel de la historia. Con la cara vuelta hacia el pasado, Aureliano ha alcanzado la misma visión de la historia que alcanzaron Melquíades y el ángel benjaminiano, pues, quitándose de la cabeza todo lo que sabe del curso sucesivo de la historia, en lo que para nosotros aparece como una cadena de acontecimientos, él ve una catástrofe única, que acumula sin cesar ruina sobre ruina y se las arroja a sus pies. [...]En esta abreviatura se contiene, en su compleja simplicidad, toda la historia de la humanidad tal y como se le debe de aparecer a Dios y tal como se le aparece a Aureliano en el instante de su culpable cognoscibilidad. No me parece casual que esta visión de la historia de la humanidad haya sido depositada en unos pergaminos escritos por alguien a quien pudimos identificar con la vieja imagen alegórica del Judío Errante. Donde los herederos de los vencedores ven una triunfal continuidad de la historia, la tradición de los vencidos - encarnada por el perseguido Melquíades - ve sólo una imparable sucesión de catástrofes. Para Melquíades, la continuidad del progreso histórico es el retorno de una idéntica dominación, ejercida cada vez de forma distinta y con distinto rostro. Por eso, la imagen del pasado en la que Aureliano se reconoce en el momento de peligro es aquella en la que el Judío Errante que pasa por el pueblo a la muerte de Úrsula, muere amarrado de un árbol (p. 98).

¿Conoció García Márquez a Benjamin antes de escribir Cien años de soledad? Salvo que lo hubiese leído en francés, es muy probable que él estuviese detrás de la recepción de Benjamin en México entre 1964 y 1971 a partir de las redes suramericanas más que alemanas directamente, pues José Emilio Pacheco en 1971 prologó la primera traducción de Benjamin en México, París capital del siglo XIX, cuya traducción había hecho Miguel González al parecer de una versión en inglés. Pacheco, además, ya había mencionado a Benjamin en la Antología del modernismo (1970). La primera mención de Benjamin en español está en la Estética (1933) de Luis Juan Guerrero y, sobre todo, en la colección de Estudios Alemanes fundada en 1964 por Rafael Gutiérrez Girardot desde Bonn, con Garzón Valdés y Álvarez Murena.

José Emilio Pacheco (1987) se preguntó si Cien años de soledad no podría ser la justificación de la época más utópica del siglo xx mexicano, la que corre entre 1962 y 1968, “enmarcada entre dos crímenes: el asesinato de Rubén Jaramillo y la matanza de Tlatelolco" (p. 3). Una respuesta parece estar, como veremos, en el común interés de Pacheco y García Márquez por el holocausto (la Shoá), es decir, por una historiografía negativa. En las últimas páginas de Cien años de soledad aparece un alter ego del autor, también llamado Gabriel, quien admite estar "encastillado en la realidad escrita” (García Márquez, 2007, p. 440). De este encastillamiento Gabriel solo parece liberarse, no en la visita a los burdeles en las noches de parranda, sino cuando 
descubre que la literatura es "el mejor juguete que se había inventado para burlarse de la gente" (p. 440). Esta burletería o "mamagallismo” esencial, que el colombiano asimiló, entre muchas otras fuentes, de las Greguerías de Gómez de la Serna, resultó tan notable en Cien años de soledad que, en 1973, Octavio Paz lo comentó en una entrevista: "El lenguaje atomizado de Gómez de la Serna es el lenguaje de la explosión: con él comienza la prosa moderna en español. La prosa del escritor colombiano, esencialmente académica, es un compromiso entre periodismo y fantasía. Poesía aguada” (citado en García Usta, 2007, p. 135). Paz acertaba en los síntomas, pero erraba en el diagnóstico. Pues, si se observa bien, García Márquez había encontrado la fórmula para salir de El laberinto de la soledad (primera edición, 1950) mediante el humorismo fomentando por el cine y la televisión a color, por los happenings y el rock and roll, por el sujeto de tipo objetivista y funcional que, abandonando la ya asfixiante estructura identitaria de la antropología de entreguerras, buscaba la velocidad, los espacios abiertos, la disolución de los nacionalismos y las ideologías. "A los filósofos se les escapa el secreto del humorismo”, escribía el propio Gómez de la Serna (2014), "porque matan el entusiasmo y la credulidad por una fría ironía” (p. 69). Consciente de no encastillarse so pena de tullirse, García Márquez buscó en México los espacios abiertos, es decir, desplegarse hacia La Habana, Bogotá, Barcelona, Moscú.

En virtud de la técnica aeronáutica y de la comunicación audiovisual, que elimina las grandes distancias, ya Heidegger (2010) había notado la agudización de una crisis del elemento presente — de la presencialidad — en favor de la aprehensión (p. 87). Macondo no puede ni quiere ser un elemento presente o presencial porque, primero, el tren lo ha conectado con el resto del mundo y, segundo, porque sus habitantes nunca lograron crear un ethos secular, esto es, un espacio público. Pero no se trata de un fenómeno particular achacable al ethos latinoamericano, sino de un fenómeno planetario en virtud del tecnicismo mediático. El nihilismo, un movimiento al fin y al cabo histórico, se advierte con mayor ahínco en aquellos que se creen libres de él, como García Márquez, capaz de saltar de La Habana a Washington y de allí Moscú, Bogotá o Barcelona.

\section{Conclusiones}

Al llegar García Márquez en 1961 a Ciudad de México ocurría una transformación radical de su trazo urbano, similar a las que efectuó el barón Haussmann en el París de mediados del siglo xıx, porque el centro de Ciudad de México había recibido la 
desconexión íntima entre la vida intelectual y la del conjunto de la sociedad. Estudiantes y profesores ya no convivían en el centro, sino que debían trasladarse hasta el sur, donde la Universidad Nacional Autónoma de México acababa de construir un campus, la Ciudad Universitaria, desconectado del resto de la sociedad. Este inmenso resto había quedado abandonado culturalmente a la manipulación televisiva (Echevarría, 2016, p. 221). La nostalgia de los estudiantes por el centro, por recuperar los antiguos espacios de la ciudad, llevó a las movilizaciones ad portas de los Juegos Olímpicos de 1968 que terminaron en la trágica matanza del 2 de octubre.

En 1960, un año antes de arribar el escritor colombiano la Ciudad de México, se inauguró el Museo Nacional de Antropología, el más grande del país y quizás de Latinoamérica. Pero en medio de aquella riqueza antropológica, en realidad, había una cultura de la pobreza. El antropólogo urbano Oscar Lewis, en Five Families: Mexican Case Studies in the Culture of Poverty (1959), parece adelantar una descripción de Macondo al otear cualquier colonia de la capital mexicana:

The people in the culture of poverty have a strong feeling of marginality, of helplessness, of dependency, of not belonging. They are like clients in their own country, convinced that the existing institutions do not save their interests and needs. Along with this feeling of powerlessness is a widespread feeling of inferiority, of personal unworthiness. This is true of the slum of Mexico City, who do not constitute a distinct ethnic or racial group and do not suffer from racial discrimination. [...] People with a culture of poverty have very little sense of history (citado por Monsiváis, 2000, p. 22).

Efectivamente, los problemas raciales o étnicos no son una fuente de conflicto en Macondo. El problema es el de la cultura de la pobreza que, a juicio de Monsiváis, no genera comunidades solidarias, sino desolaciones urbanas. Esta desolación, insistimos, es producto de una técnica que nos ha acercado, pero también cercado. El tren, el cine y el avión desaparecieron Macondo sin necesidad de tomarlo en el sentido estricto de la palabra, sino de apropiárselo inmaterialmente al dominar sus campos de percepción.

\section{Referencias bibliográficas}

Bajarlía, J. J. (2012). El Libro de los plagios. Buenos Aires: Ediciones Eslea.

Benjamin, W. (2003). La obra de arte en la era de la reproducibilidad técnica. México: Editorial Itaca.

Benjamin, W. (2008). Tesis sobre la historia y otros fragmentos. México: UACM.

Cabrera López, P. (2013). Trascendencia del suplemento “La Cultura en México”. Impossibilia 6 pp. 45-59. 
Caspistegui, F. J. (2009). El primer Koselleck: Crítica y crisis. Anthropos 223, pp. 54-70.

Cobo Borda, J. G. (2006). Lecturas convergentes. Bogotá: Taurus.

Corona Berkin, S. (1992). La televisión: informe de Salvador Novo y Guillermo González Camarena entre melón y sandía. Comunicación y Sociedad 16-17, pp. 195-238.

Echevarría, B. (2016). Modernidad y blanquitud. México: Era.

Espinosa, G. (2004). La verdad sea dicha. Mis memorias. Bogotá: Taurus.

García Usta, J. (2007). García Márquez en Cartagena: sus inicios literarios. Bogotá: Planeta.

García Márquez, G. (2007). Cien años de soledad. Madrid: RAE-Alfaguara.

Gilman, C. (2003). Entre la pluma y el fusil. Debates y dilemas del escritor revolucionario en América Latina. Buenos Aires: Siglo xxı.

Gómez de la Serna, R. (2014). Humorismo. Madrid: Casimiro.

Heidegger, M. (2010). Caminos en el bosque. Madrid: Alianza.

Hernández Lomelí, F. (2002). Racionalidad limitada y efectos perversos: Ensayo sobre el origen de la televisión en México. Anuario de Investigación de la comunicación CONEICC IX, pp. 323-345.

Jay, M (2007). Ojos abatidos. La denigración de la visión en el pensamiento francés del siglo XX. Madrid: Akal. Kittler, F. (1990). Discourse Networks, 1800/1900. Stanford: Stanford University Press.

Kittler, F. (1999). Gramaphone, Film, Typewritter. Stanford: Stanford University Press.

Kittler, F. (2010). Optical Media. Berlin Lectures 1999. Cambridge: Polity Press.

Ligensa, A. (2015). Triangulating a Turn: Film 1900 as Technology, Perception and Culture. En A. Ligensa y K. Kreimeier (Eds.). Film 1900: Technology, Perception and Culture. Bloomington: Indiana University Press.

Martin, G. (2009). Garcia Márquez. A Life. Londres. Bloomsbury

Monsiváis, C. (2000). Aire de familia: cultura y sociedad en América Latina. Anagrama: Barcelona.

Pacheco, J. E. (1987). Inventario. Antología II. 1984-1992. México: Era.

Pacheco, J. E. (2014). Asturias y Gabriel García Márquez: Epílogo de una tragicomedia. Milenio. Recuperado de: https://www.milenio.com/cultura/asturias-y-garcia-marquez-epilogo-de-una-tragicomedia $[14.02 .2021]$

Poniatowska, E. (2017). "Viví como iluminado mientras escribía”. Medio siglo de Cien años de soledad. Revista de la Universidad de México 161, pp. 67-74.

Ong, W. J. (2006). Oralidad y escritura. Tecnologias de la palabra [1982]. Buenos Aires: FCE.

Rama, A. (1981). La tecnificación narrativa. Hispamérica, 10 (30), pp. 29-82.

Reyes, A. (2004). La experiencia literaria. México: Fondo de Cultura Económica.

Rocco, A. (2014). Gabriel García Márquez and the Cinema: life and works. Nueva York: Tamesis. 
Rocco, A. (2016). La narrativa fílmica de José Emilio Pacheco: el guion cinematográfico El castillo de la pureza. Valenciana (18), pp. 9-34.

Sánchez Ruiz, E. (1991). Hacia una cronología de la televisión mexicana. Comunicación y Sociedad 10-11, pp. 235-262.

Salmerón Tellechea, C. (2011). La Salónica de un dramaturgo frustrado: metaficción y exilio en Morirás lejos. Literatura mexicana 22 (2), pp. 157-181.

Santana Acuña, A. (2020). Ascent to Glory: How One Hundred Years of Solitude Was Written and Became a Global Classic. Nueva York: Columbia University Press.

Virilio, P. (1986). Futurismo y fascismo. Los Cuadernos del Norte: Revista cultural de la Caja de Ahorros de Asturias 7 (39), pp. 4-9.

Virilio P. (1991). Guerre et cinéma. Logistique de la perception. París: Cahiers de Cinéma.

Wahnón, S. (1995). Las palabras y las cosas en Cien años de soledad. En Lenguaje y literatura. Barcelona: Ediciones Octaedro. 